AperTO - Archivio Istituzionale Open Access dell'Università di Torino

\title{
Semicontinuous nitrogen limitation as convenient operation strategy to maximize fatty acid production in Neochloris oleoabundans
}

\section{This is the author's manuscript}

Original Citation:

Availability:

This version is available http://hdl.handle.net/2318/146044

since

Published version:

DOI:10.1016/j.algal.2014.03.007

Terms of use:

Open Access

Anyone can freely access the full text of works made available as "Open Access". Works made available under a Creative Commons license can be used according to the terms and conditions of said license. Use of all other works requires consent of the right holder (author or publisher) if not exempted from copyright protection by the applicable law. 


\section{(4) \\ UNIVERSITÀ DEGLI STUDI DI TORINO}

This Accepted Author Manuscript (AAM) is copyrighted and published by Elsevier. It is posted here by agreement between Elsevier and the University of Turin. Changes resulting from the publishing process - such as editing, corrections, structural formatting, and other quality control mechanisms - may not be reflected in this version of the text. The definitive version of the text was subsequently published in Algal Research 5 (2014), DOI: http://dx.doi.org/10.1016/j.algal.2014.03.007.

You may download, copy and otherwise use the AAM for non-commercial purposes provided that your license is limited by the following restrictions:

(1) You may use this AAM for non-commercial purposes only under the terms of the CC-BY-NC-ND license.

(2) The integrity of the work and identification of the author, copyright owner, and publisher must be preserved in any copy.

(3) You must attribute this AAM in the following format: Creative Commons BY-NC-ND license (http://creativecommons.org/licenses/by-nc-nd/4.0/deed.en),

http://dx.doi.org/10.1016/j.algal.2014.03.007 


\title{
Semicontinuous Nitrogen limitation as convenient operation strategy to maximize fatty acid production in Neochloris oleoabundans
}

Francesca Bona $^{\mathrm{a}, *}$, Andrea Capuzzo ${ }^{\text {b,c }}$, Marta Franchino ${ }^{\mathrm{a}}$, Massimo Emilio Maffei ${ }^{\mathrm{b}, \mathrm{c}}$

${ }^{a}$ Department of Life Sciences and Systems Biology, Aquatic Ecosystems Unit, University of Turin, via Accademia Albertina 13, 10123 Torino, Italy

b Department of Life Sciences and Systems Biology, Plant Physiology Unit, Innovation Centre, University of Turin, Via Quarello 15/A, 10135 Torino, Italy

${ }^{\mathbf{c}}$ Biosfered S.r.l., Academic Spin Off of the University of Turin, Innovation Centre, Via Quarello

15/A, 10135 Torino, Italy

* Corresponding author

e-mail address: francesca.bona@unito.it

Tel. Number: +390116704520

\begin{abstract}
Neochloris oleoabundans is a green microalga known for the ability to increase its fatty acid (FA) content when grown under nitrogen $(\mathrm{N})$ depletion. Accumulation of FAs and their composition were compared by cultivating $N$. oleoabundans in $\mathrm{N}$ limitation and $\mathrm{N}$ depletion conditions. We adopted an innovative approach that consists in semicontinuous cultivation mode as a strategy to optimize lipid accumulation. To identify the optimal conditions for the production of different FAs, a temporal profile of how different conditions may influence the microalgae culture in terms of biomass, FA concentration and composition was evaluated. $\mathrm{N}$ limited culture attained higher values of algal productivity and total FA concentration $\left(0.42 \mathrm{mg} \mathrm{L}^{-1} \mathrm{~d}^{-1}\right.$ and $\left.91.2 \mathrm{mg} \mathrm{L}^{-1}\right)$ than $\mathrm{N}$ deplete culture $\left(0.15 \mathrm{mg} \mathrm{L}^{-1} \mathrm{~d}^{-1}\right.$ and $\left.53.2 \mathrm{mg} \mathrm{L}^{-1}\right)$. Considering lipid accumulation, concentration and percentage of triacylglycerols (TAG) increased in all culture methods, with respect to the $\mathrm{N}$ replete control. In particular, $\mathrm{N}$ limitation led to a significant increase of polyunsaturated TAG (PUFA), while $\mathrm{N}$ depletion led to the highest level of monounsaturated TAG. These results suggest that $N$. oleoabundans biomass and FAs were strongly affected by the $\mathrm{N}$ supply and that the quality of the TAG fraction could be modulated in accordance to the utilization purpose in a wide range of applications. Semicontinuous culture resulted as a promising operational strategy for FAs production. More specifically, semicontinuous cultivation coupled to $\mathrm{N}$ limitation was found to be a convenient method to increment PUFA fraction and therefore to yield a high value product.
\end{abstract}

Key-words: biomass, fatty acids, triacylglycerols, lipids, microalgal cultivation, algal productivity 


\section{Introduction}

The use of microalgae has several advantages when compared to other available feedstock (e.g., soybean, rapeseed, sunflowers and palm oil) [1]. Microalgae have higher growth rates and areal productivities of biomass and lipids than conventional crops, which eventually results in a lower demand of land area. Furthermore, since microalgae can be cultivated in non-arable land, they do not compete with agriculture. Microalgae cultivation is not seasonally limited and allows daily harvests [2]. Moreover, other compounds can be extracted from microalgae residual biomass such as polyunsatured fatty acids (PUFAs), sugars, pigments and antioxidants, that can be used in many commercial applications such as cosmetics, pharmaceutical and nutraceutical industries [3].

Recent studies highlighted that oleaginous algal strains cultivated under nitrogen $(\mathrm{N})$ deficiency increase their lipid content without a substantial decrease in biomass productivity [4,5] . Most studies report data in terms of maximum lipid content, without a correlation with the biomass productivity and without considering that the maximum lipid content is often attained when the biomass productivity is at a minimum. Instead, a key-parameter to evaluate lipid production should be lipid productivity [6], meant as the product of biomass productivity and the lipid content. In addition, lipid composition is an important aspect to be evaluated, because different fatty acids (FAs) affect the quality of the final product. Depending on the use of the oil (energy production, food or feed), the required characteristics may vary. For biodiesel production, a high presence of monounsaturated FAs (MUFA as oleic and palmitoleic acids), a reduced presence of PUFA, and a controlled saturated FA content are recommended [7,8]. On the other hand, PUFA, especially $\Omega-3$ PUFA, have been shown to be effective in preventing or treating several diseases $[9,10,11,12]$; therefore, this is the most interesting FA fraction for human as well as for animal nutrition $[13,14]$. Different cultivation conditions may affect the lipid content and the FA composition; under $\mathrm{N}$ deficiency, the protein content and the chlorophyll level decrease, while carbohydrate and lipid content increase $[15,16]$. A higher lipid content is mainly due to an accumulation of triacylglycerols (TAG), which are the preferred substrate for biodiesel production. In green algae, the variation in the FA composition usually results in increased oleic acid contents, with a consequent decrease in the average degree of polyunsaturation [17,5]. The cultivation of microalgae under $\mathrm{N}$ stress is carried out either by $\mathrm{N}$ depletion or $\mathrm{N}$ limitation. Under $\mathrm{N}$ depletion, microalgae grow in a medium lacking a $\mathrm{N}$ source, while under $\mathrm{N}$ limitation there is a constant but insufficient supply of $\mathrm{N}$. Using $\mathrm{N}$ depletion to increase the lipid content in algae, especially TAG fraction, is a well- known process $[17,2,18,19,4,5]$; whereas $\mathrm{N}$ limitation is less studied or it is meant as progressive depletion $[4,20,21]$. Neochloris oleoabundans is a microalga also known for its potential in biodiesel production $[17,22,23,18,24]$. This species when grown in batch $\mathrm{N}$ depletion may reach a total lipid content up to $40 \%[22,18]$, and has been tested in a wide range of cultural conditions $[25,26]$.

The aim of the present study is to investigate the effect on biomass growth, lipid production and FA composition of $N$. oleoabundans under $\mathrm{N}$ depletion and $\mathrm{N}$ limitation. While other studies have investigated the effect of the culture conditions on the final lipid content, lipid and biomass concentration and the temporal trend of these parameters were seldom reported. Here, a temporal profile of how different conditions (sufficient/limited/deplete) may influence the microalgal culture in term of biomass, lipid concentration and FA composition is reported, with the aim to define the optimal conditions for the production of different lipids.

\section{Materials and methods}

\subsection{Pre-cultivation conditions}

Neochloris oleoabundans UTEX 1185 was obtained from the University of Texas Culture Collection of Algae (UTEX). N. oleoabundans was inoculated in $250 \mathrm{ml}$ Erlenmeyer flasks 
containing $100 \mathrm{ml}$ of liquid medium. Flasks were maintained in sterile condition in a $\mathrm{CO}_{2}$ incubator (Sanyo $\mathrm{CO}_{2}$ Incubator Mco-19Aic) flushed with air/ $\mathrm{CO}_{2}(97 / 3, \mathrm{v} / \mathrm{v})$ to support growth and maintain $\mathrm{pH}$ within a desired range. In the incubator, the temperature was $25 \pm 2{ }^{\circ} \mathrm{C}$ and a continuous artificial illumination of $200 \mu \mathrm{mol} \mathrm{m} \mathrm{m}^{-2}$ was provided by daylight LEDs. To allow mixing of the culture an orbital shaker with $150 \mathrm{rpm}$ rotation speed was used.

The culture medium was a modified BG11 medium (MBG11), which was composed of (in $\mathrm{mg} \mathrm{L}^{-1}$ ): $1500 \mathrm{NaNO}_{3}, 20 \mathrm{Na}_{2} \mathrm{CO}_{3}, 140 \mathrm{~K}_{2} \mathrm{HPO}_{4}, 135 \mathrm{MgSO}_{4} \cdot 7 \mathrm{H}_{2} \mathrm{O}, 47 \mathrm{CaCl}_{2} \cdot 2 \mathrm{H}_{2} \mathrm{O}, 6$ citric acid, $25 \mathrm{Fe}$ (III) $\mathrm{NH}_{4}$ citrate, $1 \quad \mathrm{Na}_{2}$ EDTA, $2.86 \mathrm{H}_{3} \mathrm{BO}_{3}, \quad 1.81 \quad \mathrm{MnCl}_{2} \cdot 4 \mathrm{H}_{2} \mathrm{O}, \quad 0.39 \quad \mathrm{Na}_{2} \mathrm{MoO}_{4} \cdot 2 \mathrm{H}_{2} \mathrm{O}, \quad 0.222$ $\mathrm{ZnSO}_{4} \cdot 7 \mathrm{H}_{2} \mathrm{O}, 0.079 \mathrm{CuSO}_{4} \cdot 5 \mathrm{H}_{2} \mathrm{O}$, and $0.049 \mathrm{CoCl}_{2} \cdot 6 \mathrm{H}_{2} \mathrm{O}$. The medium $\mathrm{pH}$ was then adjusted with $1 \mathrm{M} \mathrm{HCl}$ to $\mathrm{pH} 7.0$ and autoclaved.

\subsection{Test of different culture conditions ( $N$ replete/limited/deplete)}

Tests at different $\mathrm{N}$ concentrations were performed in semicontinuous modes.

Experiments were carried out in $800 \mathrm{ml}$ glass bubble tubes containing $400 \mathrm{ml}$ culture. The daily dilution rate was $50 \%$, replaced with an equal volume of MBG11 medium containing different $\mathrm{N}$ concentrations, depending on treatments. MBG11 medium was used in $\mathrm{N}$ replete $(\mathrm{R})$. In $\mathrm{N}$ limitation (L), the $\mathrm{N}$ concentration was $10 \%$ with respect to $\mathrm{R}\left(24.75 \mathrm{mg} \mathrm{L}^{-1}\right)$; while in $\mathrm{N}$ depletion (D) the MBG11 was used with an initial $\mathrm{N}$ concentration of $24.75 \mathrm{mg} \mathrm{L}^{-1}$ and was no longer added for the rest of the experiment.

A continuous flow of air: $\mathrm{CO}_{2}(97: 3 \mathrm{v} / \mathrm{v})$ was provided in order to control $\mathrm{pH}$, ensure $\mathrm{CO}_{2}$ sufficiency and mix the culture; moreover, the temperature was maintained at $28 \pm 2{ }^{\circ} \mathrm{C}$ with an average continuous light intensity of $300 \mu \mathrm{mol} \mathrm{m} \mathrm{m}^{-2} \mathrm{~s}^{-1}$. The $\mathrm{pH}$ was measured every day and the bubbling of $\mathrm{CO}_{2}$ was regulated (range between 3 and 3.5\%) in order to maintain a $\mathrm{pH}$ in the 6.5-7.5 range. Inocula for all the experiments were obtained by centrifugation (2000 rpm for $30 \mathrm{~min})$ of biomass grown in flasks maintained in the incubator and subsequently re-suspended in a medium necessary for the experiment. For all tests, the initial biomass concentration was $0.7 \mathrm{~g} \mathrm{~L}^{-1}$ (dry weight). The test cultivation time was 7 days. All experiments were repeated in triplicate.

\subsection{Culture analysis}

Samples for dry weight (dw) calculation were taken daily in triplicate and a gravimetric determination was performed according to [27]. Samples for lipid extraction were taken from the cultures at day 0,4 and 7 , lyophilized and stored at $-20^{\circ} \mathrm{C}$.

\subsection{Lipid extraction and transesterification}

Lyophilized algae were extracted with a Soxhlet apparatus by using $\mathrm{CHCl}_{3}$-hexane $(2: 1 \mathrm{v} / \mathrm{v})$. The extract was evaporated under $\mathrm{N}_{2}$ and weighted. The extract was resuspended in hexane and then separated according to [28], by TLC in two runs: (i) hexane-diethyl ether-acetic acid, 70:30:1; (ii) hexane-diethyl ether, 95:5. After spraying with 2'-7'-dichlorofluorescein, TLC plates were observed under UV (385 nm) and spots corresponding to standards of free fatty acids (FFA; heptadecanoic acid), monoacylglycerols (MAG; monopalmitin), diacylglycerols (DAG; dilinolein) and triacylglycerols (TAG; trilinolein) were scraped off and extracted with $\mathrm{CHCI}_{3}$. Fatty acid methyl esters (FAME) were obtained, after addition of an aliquot of the internal standard heptadecanoate, by treatment with $\mathrm{MeOH}-\mathrm{BF}_{3}$ according to the method described by [29].

\subsection{Gas Chromatography and mass spectrometry}


The quantitative determination of FAME from FFA, MAG, DAG and TAG was obtained by gas chromatography by using a flame ionization detector (FID-GC $6890 \mathrm{~N}$, Agilent Technologies). A ZB5-MS 30-m column (Zebron 7HG-G010-11, Phenomenex) was used with the following temperature program: $60{ }^{\circ} \mathrm{C}$ for $1 \mathrm{~min}$ then an increasing rate of $10^{\circ} \mathrm{C} \mathrm{min}{ }^{-1}$ up to $180{ }^{\circ} \mathrm{C}$, a second increase of $1{ }^{\circ} \mathrm{C} \min ^{-1}$ up to $230^{\circ} \mathrm{C}$, then $15^{\circ} \mathrm{C} \mathrm{min}^{-1}$ to reach $290{ }^{\circ} \mathrm{C}$. The injector temperature was $280{ }^{\circ} \mathrm{C}$ and the detector $280{ }^{\circ} \mathrm{C}$; the carrier gas was $\mathrm{He}$ with a flow rate of $1 \mathrm{ml} \mathrm{min}{ }^{-1}$; splitless injection mode. Based on internal standard area, FAME from FFA, MAG, DAG and TAG were quantitatively estimated on an algae dry weight basis.

Compounds were identified by both retention times, comparison of pure standards and gas chromatography coupled to mass spectrometry (GC-MS, GC 6890N, MS 5973N, Agilent Technologies). Carrier gas was He with a constant flow of $1 \mathrm{~mL} \mathrm{~min}^{-1}$, transfer line temperature to MS Detector was $280^{\circ} \mathrm{C}$, ionization energy $70 \mathrm{eV}$, and full scan range $50-500 \mathrm{~m} / \mathrm{z}$.

The following abbreviations were used for the identified FA: C16:0= palmitic acid; C16:1= palmitoleic acid (cis-9-hexadecenoic acid); C16:2= palmitolenic acid (all-cis-9,12-hexadecadienoic acid); $\mathrm{C} 16: 3=$ all-cis-7,10,13-hexadecatrienoic acid; $\mathrm{C} 18: 0=$ stearic acid; $\mathrm{C} 18: 1=$ oleic acid (cis-9octadecenoic acid); C18:2= linoleic acid (all-cis-9,12-octadecadienoic acid); C18:3= linolenic acid (all-cis-9,12,15-octadecatrienoic acid).

\subsection{Calculations}

Biomass productivity $\left(\mathrm{mg} \mathrm{L}^{-1} \mathrm{~d}^{-1}\right)$ was calculated as the change in concentration $\left(\mathrm{mg} \mathrm{L}^{-1}\right)$ between two consecutive sampling times; specific growth rate $(\mu)$ was calculated as the change in biomass concentration (expressed as natural logarithm) as a function of time. The doubling time $\left(\mathrm{T}_{\mathrm{d}}\right)$ was calculated by dividing $\ln 2$ by the growth rate. Total fatty acids concentration $\left(\mathrm{mg} \mathrm{L}^{-1}\right)$ was calculated as the product of biomass concentration $\left(\mathrm{g} \mathrm{L}^{-1}\right)$ and total fatty acids content (TFA) (mg g 1 of biomass).

\subsection{Statistical analyses}

All data are the mean of at least three replicates. ANOVA and Tukey-Kramer's HSD test $(\mathrm{p}<0.05)$ were used to determine significant differences among different cultivation conditions on data concerning biomass, productivity and FA composition using the SYSTAT 10 software.

\section{Results and discussion}

\subsection{Biomass concentration}

Biomass concentrations of microalgae growth in $\mathrm{N}$ replete/limited/deplete conditions are shown in Figure 1.

\section{Insert Fig. 1 here}

As expected, the highest biomass concentration was achieved in $\mathrm{N}$ replete condition. After the first 3 days of adaptation phase, in $\mathrm{N}$ replete and limited cultures the daily productivity compensates the daily harvesting, thus keeping constant the algal concentration at the sampling time. This condition was maintained throughout the experiment by a constant $\mathrm{N}$ supply (Fig. 1a). The deplete culture 
never reached this equilibrium due to a progressive $\mathrm{N}$ depletion that prevented a constant increase of biomass concentration (Fig. 1b). Indeed, in the last days of depletion the dilution rate was higher than the specific growth rate, thus the system wash out gradually occurred. At the onset, the biomass concentration of deplete and limited cultures was similar. However, with increasing time, the absence of an external $\mathrm{N}$ source slowed the algal growth in deplete culture, and after the $2^{\text {nd }}$ day the biomass rapidly decreased. These results showed that culture conditions significantly $(\mathrm{p}<0.05)$ affected algae growth. Maximum, minimum and mean daily biomass productivities, growth rate and doubling time calculated for the duration of the experiments are reported in Table 1. Standard deviations are reported for all parameters except for the doubling time, which derives from the growth rate.

\section{Insert Table 1 here}

In replete conditions, the values obtained are comparable with those found in recent studies [30,26,31]. As observed with biomass values, maximum, minimum and mean productivities and growth rates increased along with $\mathrm{N}$ supply (Table 1 ). The only exception was the maximum biomass productivity, that was higher in $\mathrm{N}$ depletion than in $\mathrm{N}$ limitation, but this value was obtained at the onset, when the depletion was not effective yet. Biomass productivities were significantly different among the three cultivation conditions $(p<0.05)$. The differences among them were even more evident in terms of cumulate biomass $(\mathrm{g})$. The latter was calculated by adding the biomass harvested daily (Fig. 1b). Values reported were calculated by considering $1 \mathrm{~L}$ of initial volume.

The biomass productivity value obtained under $\mathrm{N}$ limited conditions was higher than that obtained by [32], who reported a biomass productivity of nearly $0.3 \mathrm{~g} \mathrm{~L}^{-1} \mathrm{~d}^{-1}$. Most literature data refer to batch conditions. For example, Gouveia and Oliveira [2] found an average biomass productivity of $0.09 \mathrm{~g} \mathrm{~L}^{-1} \mathrm{~d}^{-1}$ testing $N$. oleoabundans in polyethylene bags under replete conditions using a light intensity of $150 \mu \mathrm{mol} \mathrm{m} \mathrm{m}^{-2} \mathrm{~s}^{-1}$. Breuer et al. [5] cultivated $N$. oleoabundans in $\mathrm{N}$ replete and deplete conditions when the culture was maintained in flask in batch mode; they found a much higher biomass productivity compared to [2] and a low difference between the replete and the deplete conditions ( $0.45 \mathrm{~g} \mathrm{~L}^{-1} \mathrm{~d}^{-1}$ and $0.43 \mathrm{~g} \mathrm{~L}^{-1} \mathrm{~d}^{-1}$ respectively).

\subsection{Total Fatty Acids production}

Deplete cultures achieved the highest TFA contents (13.0 and $47.1 \%$ of biomass after 4 and 7 days respectively, Table 2). For the same strain, in [26] it is reported a TFA content of $18.1-18.5 \%$ in $\mathrm{N}$ depletion at $\mathrm{pH} 8.2$ with a significant increase $(29.2 \%)$ at $\mathrm{pH} 10$. In enriched natural seawater, Popovich et al. [30] found a lipid content of $26.7 \%$ after six days of $\mathrm{N}$ depletion. For Nannochloropsis, values ranging from 14.7 up to $32.5 \%$ in a similar temporal $\mathrm{N}$ deprivation were obtained in [4]. In our study, limitation showed a considerable increase of TFA content during time (1.6, 5.1 and $11.1 \%$ at day 0,4 and 7 respectively, Table 2). When only TFA production is considered, depletion could appear as the preferred method to produce TFA, but this outcome is reversed when biomass and total productivity data are considered. Until the $4^{\text {th }}$ day, the reduction of biomass production in deplete culture did not affect TFA concentration, but at the $7^{\text {th }}$ day the influence of the biomass increased, causing an increase in TFA concentration $\left(91.2 \mathrm{mg} \mathrm{L}^{-1}\right)$ in limited culture (Fig.2), which was nearly 8 times higher than the initial concentration. Also Santos et al. [33] found the highest TFA content (42.4\%) under the highest stress level (pH 10, $\mathrm{N}$ depletion and high irradiance), but the highest TFA productivity $\left(176 \mathrm{mg} \mathrm{L}^{-1} \mathrm{~d}^{-1}\right)$ at a lower stress level ( $\mathrm{pH} 8$, $\mathrm{N}$ depletion and high irradiance). Our results showed that limitation optimizes biomass and TFA production. Therefore, semicontinuous culture process positively affected lipid accumulation, in accordance with [32], in which Chlorella sp. was cultivated under batch urea progressive depletion and semicontinuous urea limitation. They found a higher lipid production using semicontinuous 
mode rather than using batch or fed-batch modes. The semicontinuous mode achieved the highest lipid productivity when compared to previous studies that were mostly focused on batch cultivation with $\mathrm{N}$ depletion. Under those conditions, Takagi et al. [34] demonstrated that limitation achieved a higher lipid and TG content compared to progressive depletion in Nannochloris sp. A further increase in TFA production can be attained optimizing other parameters (nutrient concentrations, dilution rates, irradiance) as performed in [35] using the marine Nannochloropsis gaditana.

\section{Insert Fig. 2 here}

\subsection{Fatty Acids composition}

\subsubsection{Triacylglycerols}

In accordance with previous works $[23,30]$, the general FA composition in the TAG fractions of $N$. oleoabundans had a higher content of oleic acid (C18:1) followed by palmitic (C16:0) and stearic (18:0) acids (Table 3); however, some differences among culture methods could be observed.

In nitrogen limitation conditions the saturated fraction of triglycerides decreased significantly in favor to MUFA and, in particular, PUFA (1.6 and 1.5 times at 4 and 7 days, respectively, Table 3). This trend was not observed in nitrogen replete. In nitrogen depletion conditions, saturated and polyunsaturated fatty acids slightly but significantly decreased in favor to the MUFA fraction. Regarding triglycerides quantity, the highest value was reached after 7 days of nitrogen depletion $\left(344.39 \mathrm{mg} \mathrm{g}^{-1}\right)$. After 7 days of nitrogen limitation, significantly similar values were obtained with respect to the $4^{\text {th }}$ day of depletion (85.01 and $88.24 \mathrm{mg} \mathrm{g}^{-1}$ respectively).

\subsubsection{Free fatty acids}

After 7 days of cultivation, with respect to the nitrogen replete, limited and deplete cultures showed a significant decrease of PUFA and MUFA in favor to saturated fatty acids. As for TAG, after 7 days the highest FFA content was also observed under nitrogen depletion (57.28 $\mathrm{mg} \mathrm{g}^{-1}$, Table 4).

\subsubsection{Monoacylglycerols and Diacylglycerols}

The percentage of the MAG fraction did not increase with respect to the controls during the cultivation period (Table 4). At the $4^{\text {th }}$ day in both treatments, DAG fraction percentage increased (2.7 and 2.1 times for limitation and depletion respectively); however, at the $7^{\text {th }}$ day values decreased as reported in Table 2. In both N-limited and deplete cultures, a decrease of the DAG fraction precursors (FFA and MAG) was observed at 4 days of treatment. After 7 days, DAG percentage decreased in favor of TAG accumulation.

Considering the percentage of TAG with respect to the sum of the other fractions (DAG, MAG and FFA) (Table 2), the overall ratio increased in all treatments with respect to the $\mathrm{N}$ replete control. In particular, the highest percentage values were observed under nitrogen limitation after 7 days $(76.4 \%)$ with respect to nitrogen depletion $(73.2 \%)$. These values are comparable to the $78.2 \%$ of TAGs found in [30] by cultivating $N$. oleoabundans in batch mode under nitrogen depletion (78\%). A different FA accumulation (higher under $\mathrm{N}$ depletion) might suggest a relation between lipid accumulation and the different cell culture density, as reported in [18]. Moreover, in [17] an increasing saturation level of FAs with increasing $\mathrm{N}$ limitation was reported. This was also observed in FFA fractions from saturated FA (32.4 - 38.5 \%) in N replete cultures, to higher values observed in $\mathrm{N}$ limitation and $\mathrm{N}$ depletion (54.9 - 58.1\% and 54.5 - 71.5\%, respectively). An opposite trend was observed in the TAG fraction, where the FA saturation level decreases in favor of PUFA increase under $\mathrm{N}$ limitation. On the other hand, under $\mathrm{N}$ depletion an increment of monounsaturated FA was observed, as found in [30] in batch cultivation under $\mathrm{N}$ stress.

In general, the trends obtained with a semicontinuous cultivation technique and different $\mathrm{N}$ concentrations indicate that FA saturation can be influenced by $\mathrm{N}$ nutrition, affecting the total FA content. 
Insert Table 2 here

Insert Table 3 here

Insert Table 4 here

\section{Conclusions}

This study shows that biomass and TFA are strongly affected by the cultivation method. TFA concentration was positively affected by $\mathrm{N}$ limitation, which maximized biomass production and TFA accumulation. Semicontinuous is confirmed as an effective cultivation method as it allows a greater availability of light per cell when compared to batch mode [18,19]. In semicontinuous culture, the biomass concentration can be controlled by varying the dilution rate and it can attain a constant biomass concentration for extended time.

With respect to $\mathrm{N}$ depletion cultures, $\mathrm{N}$ limitation and $\mathrm{N}$ replete under batch cultivation imply self shading limitation due to higher biomass concentration, whereas semicontinuous culture allows a greater light availability especially in $\mathrm{N}$ limited cultures. This can affect the biomass productivity as well as doubling time and other parameters.

Our methodological approach allowed us to highlight quantitative differences under different nutrition conditions; this can be a valuable information for the commercial use of microalgae for FA production. By differentially using these three cultivation methods, the quality of the TAG as well as the other fractions can be modulated depending on the utilization purpose.

Further optimization of semicontinuous cultivation, concerning for instance irradiance, dilution rates and culture media, may be a goal for future investigations.

\section{Acknowledgements}

This work was partly supported by Finpiemonte, project AlgaeNRG and by two grants from the Doctoral School of Sciences and Innovative Technologies, University of Turin. The authors are grateful to Rocco Mussat Sartor, Elena Ghiglione, Angelica Lucrezia Gibiino and Ambra Giuganino for their help in lipid extraction.

\section{References}

[1] Chisti, Y., 2007. Biodiesel from microalgae. Biotechnol. Adv. 25, 294-306.

[2] Gouveia, L., Oliveira, A.C., 2009. Microalgae as a raw material for biofuels production. J. Ind. Microbiol. Biotechnol. 36, 269-274.

[3] Mata, T.M., Martins, A.A., Caetano, N.S., 2010. Microalgae for biodiesel production and other applications: a review. Renew. Sustain. Ener. Rev. 14, 217-232. 
[4] Rodolfi, L., Chini Zittelli, G., Bassi, N., Padovani, G., Biondi, N., Bonini, G., Tredici, M.R., 2009. Microalgae for oil: strain selection, induction of lipid synthesis and outdoor mass cultivation in a low-cost photobioreactor. Biotechnol. Bioeng. 102, 100-12.

[5] Breuer, G., Lamers, P.P., Martens, D.E., Draaisma, R.B., Wijffels, R.H., 2012. The impact of N starvation on the dynamics of triacylglycerol accumulation in nine microalgae strains. Bioresour. Technol. 124, 217-226.

[6] Griffiths, M.J., Harrison, S.T.L., 2009. Lipid productivity as a key characteristic for choosing algal species for biodiesel production. J. Appl. Phycol. 21, 493-507.

[7] Pinzi, S., Garcia, I.L., Lopez-Gimenez, F.J., de Castro, M.D., Dorado, G., Dorado, M.P., 2009. The ideal vegetable oil-based biodiesel composition: a review of social, economical and technical implications. Energy Fuels 23, 2325-2341.

[8] Stansell, G.R., Gray, V.M., Sym, S.D., 2012. Microalgal fatty acid composition: implications for biodiesel quality. J. Appl. Phycol. 24, 791-801.

[9] Simopoulos, A.P., 1999. Essential fatty acids in health and chronic disease. Am. J. Clin. Nutr. 70, 560S-569S.

[10] Trautwein, E.A., 2001. N-3 Fatty acids - physiological and technical aspects for their use in food. Eur. J. Lipid Sci. Technol. 103, 45-55.

[11] Andrich, G., Nesti, U., Venturi, F., Zinnai, A., Fiorentini, R., 2005. Supercritical fluid extraction of bioactive lipids from the microalga Nannochloropsis sp. Eur. J. Lipid Sci. Technol. 107, 381-386.

[12] Mimouni, V., Ulmann, L., Pasquet, V., Mathieu, M., Picot, L., Bougaran, G., Cadoret, J.P., Morant-Manceau, A., Schoefs, B., 2012. The potential of microalgae for the production of bioactive molecules of pharmaceutical interest. Curr. Pharm. Biotechnol. 13, 2733-2750.

[13] Patil, V., Kallqvist, T., Olsen, E., Vogt, G., Gislerod, H.R., 2007. Fatty acid composition of 12 microalgae for possible use in aquaculture feed. Aquacult. Int. 15, 1-9.

[14] Christaki, E., Karatzia, M., Florou-Paneri, P., 2010. The use of algae in animal nutrition. J. Hell. Vet. Med. Soc. 61, 267-276.

[15] Jiang, Y., Yoshida, T., Quigg, A., 2012. Photosynthetic performance, lipid production and biomass composition in response to nitrogen limitation in marine microalgae. Plant Physiol. Biochem. 54, 70-77.

[16] Klok, A.J., Martens, D.E., Wijffels, R.H., Lamers, P.P., 2013. Simultaneous growth and neutral lipid accumulation in microalgae. Bioresour. Technol. 134, 233-243.

[17] Tornabene, T.G., Holzer, G., Lien, S., Burris, N., 1983. Lipid composition of the N starved green alga Neochloris oleoabundans. Enzyme Microb. Technol. 5, 435-440. 
[18] Pruvost, J., Van Vooren, G., Cogne, G., Legrand, J., 2009. Investigation of biomass and lipids production with Neochloris oleoabundans in photobioreactor. Bioresour. Technol. 100, 5988-5995.

[19] Pruvost, J., Van Vooren, G., Van Gouic, B., Le Couzinet-Mossion, A., Legrand, J., 2011. Systematic investigation of biomass and lipid productivity by microalgae in photobioreactors for biodiesel application. Bioresour. Technol. 102, 150-158.

[20] Feng, P., Deng, Z., Hu, Z., Fan, L., 2011. Lipid accumulation and growth of Chlorella zofingiensis in flat plate photobioreactors outdoors. Bioresour. Technol. 102, 10577-10584.

[21] Harwati, T.U., Willke, T., Vorlop, K.D., 2012. Characterization of the lipid accumulation in a tropical freshwater microalgae Chlorococcum sp. Bioresour. Technol. 121, 54-60.

[22] Li, Y., Horsman, M., Wang, B., Wu, N., Lan, C.Q., 2008. Effects of N sources on cell growth and lipid accumulation of green alga Neochloris oleoabundans. Appl. Microbiol. Biotechnol. 81, 629-636.

[23] Gouveia, L., Evangelista, A., Lopes, T., Reis, A., 2009. Neochloris oleabundans UTEX \#1185: a suitable renewable lipid source for biofuel production. J. Ind. Microbiol. Biotechnol. 36, 821-826.

[24] Wang, B., Lan, C.Q., 2011. Optimising the lipid production of the green alga Neochloris oleoabundans using box-behnken experimental design. Can. J. Chem. Eng. 89, 932-939.

[25] Franchino, M., Comino, E., Bona, F., Riggio, V.A., 2013. Growth of three microalgae strains and nutrient removal from an agro-zootechnical digestate. Chemosphere 92 (6), 738-744.

[26] Santos, A. M., Lamers, P. P., Janssen, M., Wijffels, R. H., 2013. Biomass and lipid productivity of Neochloris oleoabundans under alkaline-saline conditions. Algal Research, 2(3), 204-211.

[27] Chini Zitelli, G., Pastorelli, R., Tredici, M.R., 2000. A modular Flat Panel Photobioreactor (MFPP) for indoor mass cultivation of Nannochloropsis sp. under artificial illumination. J. Appl. Phycol. 12, 521-526.

[28] Stobart, A.K., Stimne, S., 1990. Triacylglycerol biosynthesis, in: Harwood, J.L., Bowyer, J.R. (Eds.), Methods in Plant Biochemistry. Academic Press, London, pp. 19-46.

[29] Horowitz, W., 1970. Official Methods of Analysis of the Association of Official Analytical Chemists, eleventh ed. Association of Official Analytical Chemists, Washington D.C.

[30] Popovich, C.A., Damiani, C., Constenla, D., Martinez, A.M., Freije, H., Giovanardi, M., Pancaldi, S., Leonardi, P.I., 2012. Neochloris oleoabundans grown in enriched natural seawater for biodiesel feedstock: evaluation of its growth and biochemical composition. Bioresour. Technol. $114,287-293$.

[31] Sousa, C., Compadre, A., Vermuë, M. H., Wijffels, R. H., 2013. Effect of oxygen at low and high light intensities on the growth of Neochloris oleoabundans. Algal Research, 2(2), 122-126.

[32] Hsieh, C.H., Wu, W.T., 2009. Cultivation of microalgae for oil production with a cultivation strategy of urea limitation. Bioresour. Technol. 100, 3921-3926. 
[33] Santos, A.M., Wijffels, R. H, Lamers, P. P., 2014. pH-upshock yields more lipids in nitrogenstarved Neochloris oleoabundans. Bioresour. Technol 152, 299-306.

[34] Takagi, M., Watanabe, K., Yamaberi, K., Yoshida, T., 2000. Limited feeding of potassium nitrate for intracellular lipid and triglyceride accumulation of Nannochloris sp. UTEX LB1999. Appl. Microbiol. Biotechnol. 54, 112-117.

[35] San Pedro, A., Gonzalez-Lopez, C.V., Acién, F.G., Molina-Grima, E., 2013. Marine macroalgae selection and culture conditions optimization for biodiesel production. Bioresour. Technol. 134, 353-361. 


\section{Table 1}

Biomass productivity $(\mathrm{P})$, specific growth rate $(\mu)$ and doubling time $\left(\mathrm{T}_{\mathrm{d}}\right)$ in N replete, limited and deplete cultures.

\begin{tabular}{ccccc}
\hline & & N-Replete & N-Limited & N-Deplete \\
\hline Biomass & Max & $0.81 \pm 0.06$ & $0.56 \pm 0.06$ & $0.66 \pm 0.07$ \\
productivity & Min & $0.59 \pm 0.05$ & $0.26 \pm 0.06$ & $-0.01 \pm 0.01$ \\
$(\mathrm{P})\left(\mathrm{g} \mathrm{L}^{-1} \mathrm{~d}^{-1}\right)$ & Mean & $0.69 \pm 0.08$ & $0.42 \pm 0.19$ & $0.15 \pm 0.02$ \\
& & & & \\
& & & & \\
& & & & \\
Specific Growth rate $(\mu)$ & $0.69 \pm 0.05$ & $0.58 \pm 0.12$ & $0.26 \pm 0.02$ \\
& & 1 & 1.19 & 2.65 \\
Doubling Time $\left(\mathrm{T}_{\mathrm{d}}\right)$ & & & \\
\hline
\end{tabular}

\section{Table 2}

Summary of fraction percentages and total fatty acids content (percentage on biomass dry weight). In the same row, different letters indicate significant $(\mathrm{p}<0.05)$ differences, while identical letters indicate grouping of values with no significant $(\mathrm{p}>0.05)$ differences.

\begin{tabular}{c|c|cc|cc|c|c|} 
& & \multicolumn{2}{|c|}{ N Replete } & \multicolumn{2}{c|}{ N Limited } & \multicolumn{2}{c|}{ N Deplete } \\
& Time 0 & Time 4 & Time 7 & Time 4 & Time 7 & Time 4 & Time 7 \\
\hline TAG & $68.9 \pm 0.4^{\mathrm{a}}$ & $45.3 \pm 0.2^{\mathrm{b}}$ & $22.6 \pm 0.1^{\mathrm{c}}$ & $62.4^{\mathrm{a}} \pm 0.3^{\mathrm{d}}$ & $76.4 \pm 0.5^{\mathrm{e}}$ & $68.0 \pm 4.0^{\mathrm{a}}$ & $73.2 \pm 1.0^{\mathrm{a}, \mathrm{e}}$ \\
Free FA & $17.6 \pm 0.1^{\mathrm{a}}$ & $40.8 \pm 0.3^{\mathrm{b}}$ & $43.7 \pm 0.2^{\mathrm{c}}$ & $8.7 \pm 0.1^{\mathrm{d}}$ & $6.3 \pm 0.1^{\mathrm{e}}$ & $11.7 \pm 0.1^{\mathrm{f}}$ & $12.2^{\mathrm{a}} \pm 0.1^{\mathrm{g}}$ \\
MAG & $7.6 \pm 1.1^{\mathrm{a}}$ & $6.1 \pm 0.6^{\mathrm{a}, \mathrm{c}}$ & $18.3 \pm 1.7^{\mathrm{b}}$ & $7.2 \pm 0.6^{\mathrm{a}}$ & $4.4 \pm 0.4^{\mathrm{c}, \mathrm{d}}$ & $3.2 \pm 0.1^{\mathrm{d}}$ & $4.7 \pm 0.6^{\mathrm{c}, \mathrm{d}}$ \\
DAG & $6.0 \pm 0.3^{\mathrm{a}}$ & $7.9 \pm 1.1^{\mathrm{a}}$ & $15.4 \pm 2.0^{\mathrm{b}}$ & $21.7 \pm 2.2^{\mathrm{c}}$ & $12.9 \pm 1.6^{\mathrm{b}, \mathrm{d}}$ & $17.1 \pm 1.5^{\mathrm{b}}$ & $9.9 \pm 1.3^{\mathrm{a}, \mathrm{d}}$ \\
\hline TFA & $1.62 \pm 0.03^{\mathrm{a}}$ & $2.40 \pm 0.06^{\mathrm{b}}$ & $1.38 \pm 0.06^{\mathrm{c}}$ & $5.08 \pm 0.16^{\mathrm{d}}$ & $11.12 \pm 0.27^{\mathrm{e}}$ & $12.98 \pm 0.73^{\mathrm{f}}$ & $47.05 \pm 1.36^{\mathrm{g}}$
\end{tabular}




\section{Table 3}

Triglycerides composition (values are expressed as $\mu \mathrm{g}$ or mg per grams of biomass dry weight). In the same row, different letters indicate significant ( $\mathrm{p}<0.05$ ) differences, while identical letters indicate grouping of values with no significant $(\mathrm{p}>0.05)$ differences.

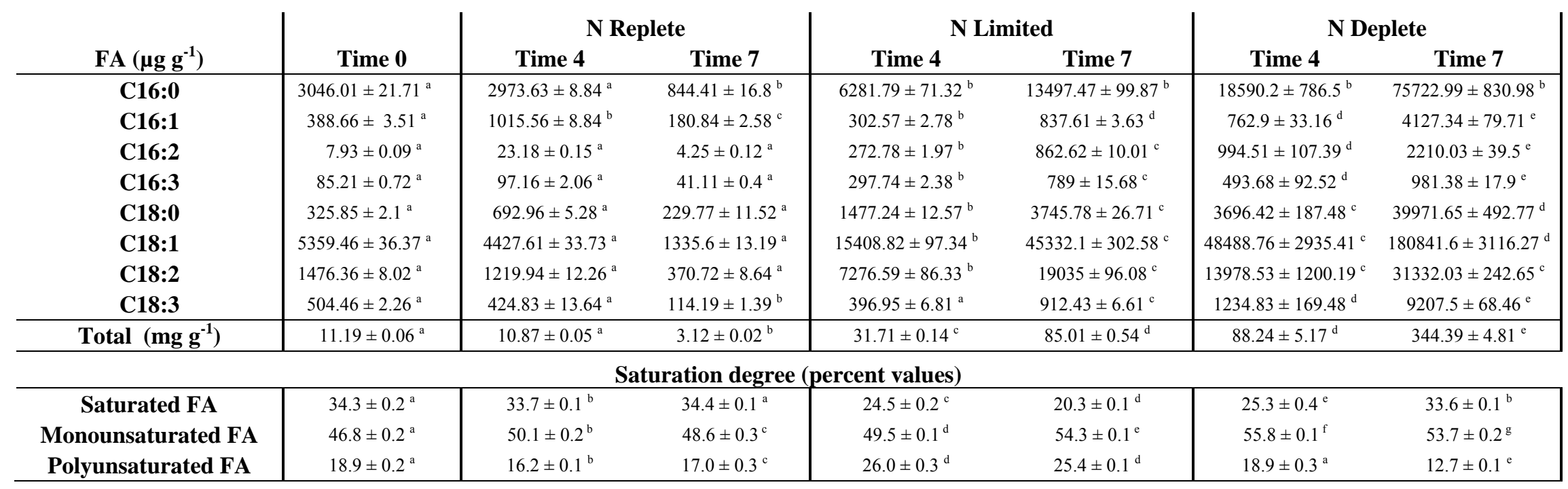




\section{Table 4}

Free fatty acids, mono- and diacylglycerols composition in semicontinuous cultivation (values are expressed as mg per grams of biomass dry weight) and saturation level (expressed as percentage with respect to total) of free fatty acids. In the same row, different letters indicate significant $(\mathrm{p}<0.05)$ differences, while identical letters indicate grouping of values with no significant $(\mathrm{p}>0.05)$ differences.

\begin{tabular}{|c|c|c|c|c|c|c|c|}
\hline & \multirow[b]{2}{*}{ Time 0} & \multicolumn{2}{|c|}{ N Replete } & \multicolumn{2}{|c|}{ N Limited } & \multicolumn{2}{|c|}{ N Deplete } \\
\hline & & Time 4 & Time 7 & Time 4 & Time 7 & Time 4 & Time 7 \\
\hline MAG (mg g $\left.{ }^{-1}\right)$ & $1.23 \pm 0.17^{\mathrm{a}, \mathrm{b}}$ & $1.46 \pm 0.15^{\mathrm{a}}$ & $2.52 \pm 0.23^{\mathrm{a}, \mathrm{b}}$ & $3.67 \pm 0.3^{\mathrm{a}, \mathrm{b}}$ & $4.85 \pm 0.4^{\mathrm{b}}$ & $4.11 \pm 0.17^{\mathrm{a}, \mathrm{b}}$ & $22.32 \pm 2.67^{\mathrm{c}}$ \\
\hline DAG (mg g $\left.{ }^{-1}\right)$ & $0.97 \pm 0.05^{\mathrm{a}}$ & $1.9 \pm 0.27^{\mathrm{a}}$ & $2.13 \pm 0.28^{\mathrm{a}}$ & $11.05 \pm 1.13^{b}$ & $14.3 \pm 1.78^{b}$ & $22.23 \pm 1.89^{c}$ & $46.62 \pm 5.99^{\mathrm{d}}$ \\
\hline FFA $\left(\mathrm{mg} \mathrm{g}^{-1}\right)$ & $2.85 \pm 0.02^{\mathrm{a}}$ & $9.79 \pm 0.08^{b}$ & $6.04 \pm 0.03^{c}$ & $4.4 \pm 0.04^{\mathrm{d}}$ & $7.05 \pm 0.03^{\mathrm{e}}$ & $15.24 \pm 0.11^{\mathrm{f}}$ & $57.28 \pm 0.11^{\mathrm{g}}$ \\
\hline Saturated FFA & $46.7 \pm 0.5^{\mathrm{a}}$ & $38.5 \pm 0.4^{\mathrm{b}}$ & $32.4 \pm 0.2^{\mathrm{c}}$ & $54.9 \pm 0.3^{\mathrm{d}}$ & $58.1 \pm 0.1^{\mathrm{e}}$ & $54.5 \pm 0.1^{\mathrm{d}}$ & $71.5 \pm 0.2^{f}$ \\
\hline Monounsaturated FFA & $24.1 \pm 0.3^{\text {a }}$ & $37.9 \pm 0.3^{\mathrm{b}}$ & $40.2 \pm 0.2^{c}$ & $30.4 \pm 0.2^{d}$ & $26.9 \pm 0.1^{\mathrm{e}}$ & $37.4 \pm 0.2^{b}$ & $22.6 \pm 0.1^{\mathrm{f}}$ \\
\hline Polyunsaturated FFA & $29.2 \pm 0.2^{\mathrm{a}}$ & $23.5 \pm 0.7^{\mathrm{b}}$ & $27.5 \pm 0.1^{\mathrm{c}}$ & $14.7 \pm 0.1^{\mathrm{d}}$ & $15.0 \pm 0.1^{\mathrm{d}}$ & $8.2 \pm 0.1^{\mathrm{e}}$ & $5.9 \pm 0.1^{\mathrm{f}}$ \\
\hline
\end{tabular}



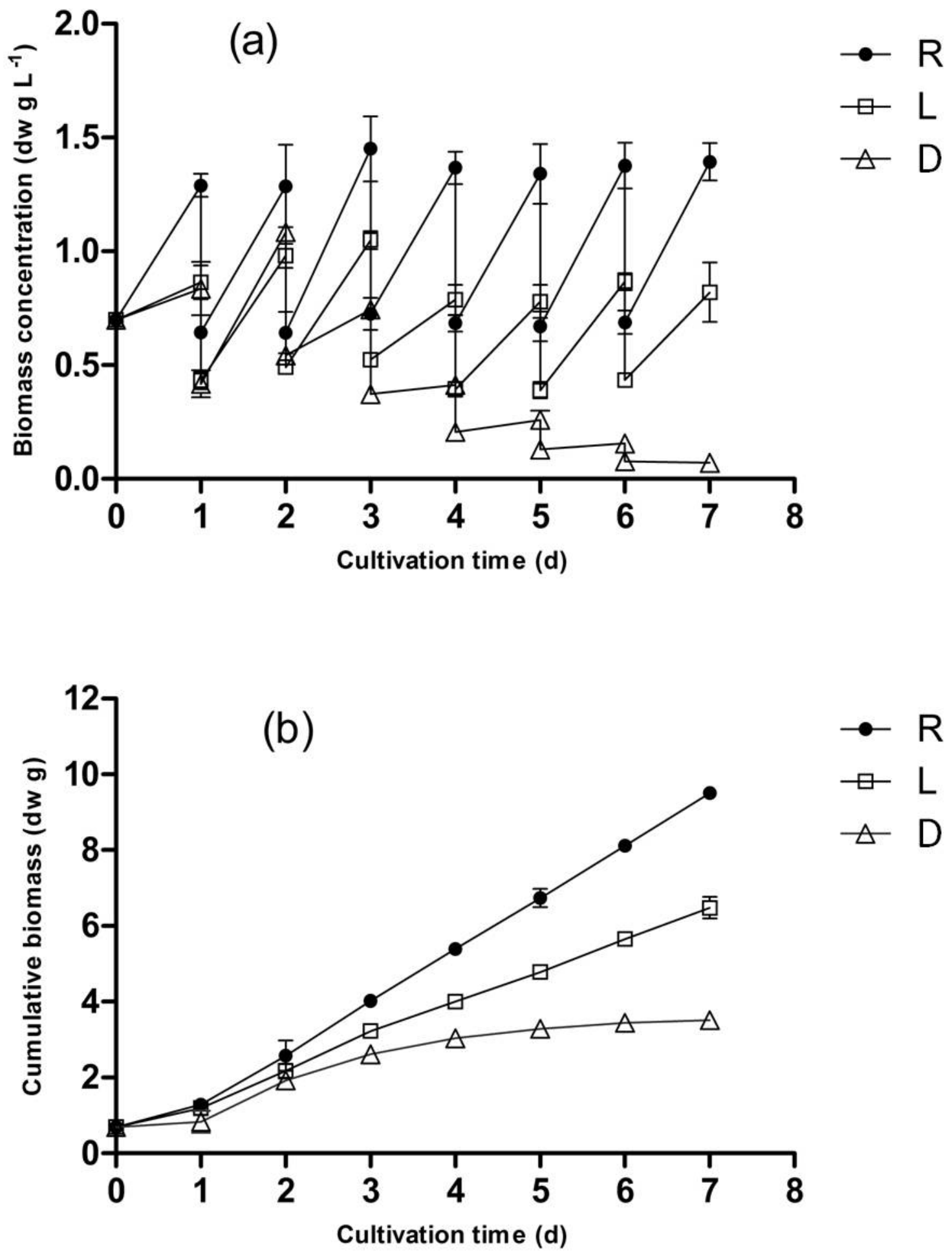

Fig. 1. a) Biomass concentration and b) cumulative biomass of replete (R), limited (L) and deplete (D) cultures 


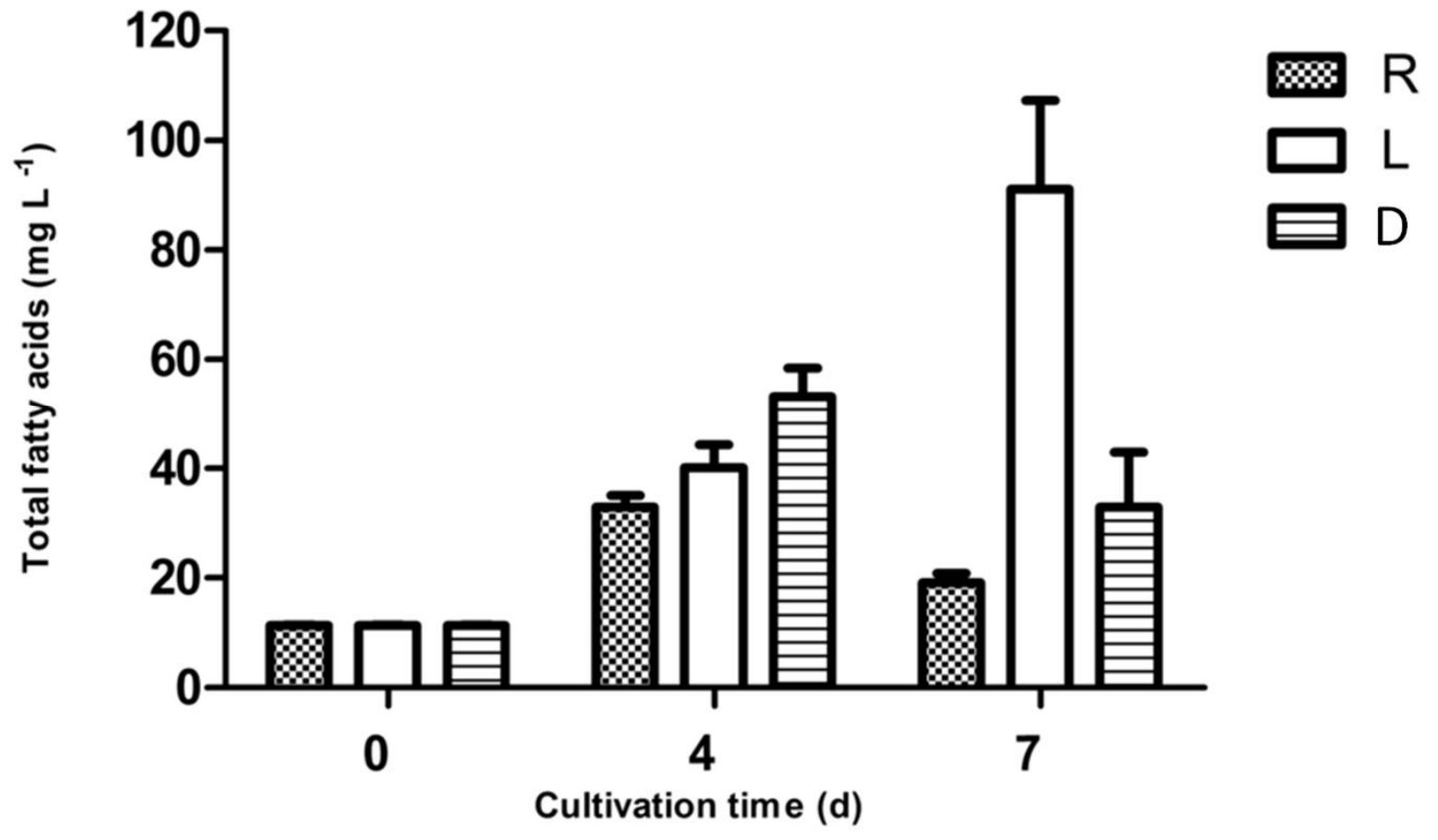

Fig.2. Total fatty acids (TFA) $\left(\mathrm{mg} \mathrm{L}^{-1}\right)$ in replete (R), limitation (L) and deplete (D) 